\title{
IFPR
}

\section{LAND PLOT SIZE, MACHINE USE AND AGRICULTURAL INTENSIFICATION IN CHINA}

\section{YANYAN LIU AND YUAN ZHOU}

China has experienced unprecedented economic achievement for more than three decades and remains one of the fastest growing economies in the world. Rapid urbanization and development of the non-farm economy have led to massive movements of labor from rural to urban areas, leaving agricultural production mostly in the hands of female and senior farmers. Due to considerable surplus labor in rural areas, these changes did not raise concerns about agricultural production until recently, when the rural real wage experienced a sharp rise, signaling the exhaustion of this surplus. Since 2010, China has changed from a net exporter to a net importer of grains. Currently, China's self-sufficiency ratio of wheat, rice and corn is about $95 \%$. About $80 \%$ of consumed soybean and other agri-products, such as milk and sugar, are imported. As the world's most populous country, further reduction of self-sufficient ratio of major agri-products could lead to problems in food security world-wide.

In order to maintain agricultural production as labor costs continue to rise, agricultural labor input will need to be substituted with machine input. China's farming system, like that of many Asian Countries, is characterized by small landholdings, a high degree of land fragmentation, and high intensification at both the intensive and extensive margin. Although China has experienced rapid farm mechanization in recent decades thanks to the rapid development of machinery rental markets, the extent to which mechanization can be realized in China's farming system remains a critical question. Small plot size poses serious constraints for mechanization because of scale economies of machine. In addition, a considerable amount of China's land is located in hills or mountains, posing further difficulties for mechanization.

Recently we completed a study to explore the extent to which small plot size deters mechanization in China and the implications for agricultural production, specifically the number of cultivating seasons per year. In our field trips in China, we often observed that small plots were less frequently cultivated; the farmers we interviewed attributed this reduced intensification to the difficulty of using machines on small plots, especially if these plots are in mountainous and hilly areas. Cultivating in these small plots become less worthwhile when labor costs increase.

\section{DATA AND DESCRIPTIVE EVIDENCE}

Our data come from a three-round household survey conducted in 2001, 2009 and 2013. The survey covers 1,100 panel farm households from six provinces. Figure 1 plots the sample villages. In the 2013 round, we collected additional information on the use of machinery for each major farming activity (such as land preparation, fertilizer and pesticide/herbicide application, and harvesting) for each plot/parcel of land in order to examine the scale effects of machine use at different production stages.

After dropping the non-cultivating households (i.e., the households that rented out all of their land), the 2013 survey provides a sample of 2,860 plots cultivated by 879 households. The sample mean of landholdings is $11.6 \mathrm{mu}$ (about $0.77 \mathrm{ha}$ ) while the median is $4.8 \mathrm{mu}$ (about 0.32 ha). About 93 percent households cultivated land less than $30 \mathrm{mu}$ ( $2 \mathrm{ha}$ ) and 65 percent cultivated land less than $7.5 \mathrm{mu}(0.5 \mathrm{ha})$. In addition to these small landholdings, the land is often fragmented. A median household cultivated three plots. About 82 percent households cultivated more than one plot, while 22 percent cultivated five or more plots. Among the plots cultivated by the sample households, 1,941 plots are located in plains and 893 are located in hilly or mountainous areas. The plots located in hilly or mountainous areas account for 15.4 percent of the total area of cultivated land in the sample.

Figure 2 depicts proportion of machine use by production stage (land preparation, fertilizer/pesticide application, and harvest) conditional on plot size. Machine use at each production stage increased monotonically in plot size, pointing to the existence of scale economies.

We further describe machine use patterns versus plot size for plots in plains and for plots in hills or mountains. Figures 3-6 depict the proportion of machine use conditional on plot size by location at three production stages: land preparation, fertilizer/pesticide application, and harvest, respectively. Machine use increases monotonically for both types of plots. Notably, the curves for plots in hills or mountains are placed significantly lower than the curves for plots in plains at each production stage, suggesting that machine adoption is much lower in hilly/mountainous plots at each plot size. We also find that the curves for plots in hills or mountains are flatter than those for plots in plains, which suggests that the scale economies of machine use are weaker for hilly/mountainous plots. 


\section{EMPIRICAL FINDINGS}

We estimate machine use as a function of plot size, plot quality, and other plot-level variables while controlling for household fixed effects that account for socio economic factors (such as shadow prices of inputs, liquidity constraints, knowledge, and preferences). This specification thus captures the scale economies of machine use. We focus our analysis on the plots allocated to households to avoid the possible endogeneity arising from unobservable characteristics of rented land. We find that machine use shows significant economies of scale which are more pronounced i) at the harvest stage than at land preparation, and ii) for plots located in plains than those in hills or mountains.

Our findings on scale effects of machinery adoption suggest that small plots and plots located in hills or mountains face higher costs for machine use. These higher costs, combined with sharply increased labor costs, makes planting on small plots and on plots in hills or mountains less worthwhile. We explore the changes in number of crop planting seasons per year by plot size, using the three-year household panel. We find that number of planting seasons have reduced from 2000 to 2013 and such pattern is more pronounced i) for small plots than large ones and ii) for plots located in plains than those in hills or mountains.

\section{POLICY IMPLICATIONS}

The Government of China has taken a number of measures to encourage the growth of larger farms, as well as a more consolidated landholding structure. These measures include the provision of more secure land titles, the facilitation of land rental transactions, the provision of subsidized loans to large farms, etc. Our results suggest that these measures will likely be more effective for plots located in plains than for those located in hilly or mountainous areas; however, the latter account for a non-negligible share of China's total agricultural land. With continuing increases in labor costs, we would expect these hilly/mountainous plots to be less cultivated. Our findings also suggest that mechanization will likely increase rental prices for plots in the plains and reduce those for plots in the hills and mountains.

Will the expected increases in land productivity sufficiently make up for the loss of output from the reduced intensification of marginalized plots? How will increased rental prices in the plains affect the well-being of the farmers cultivating the marginalized plots? These questions warrant further investigation.

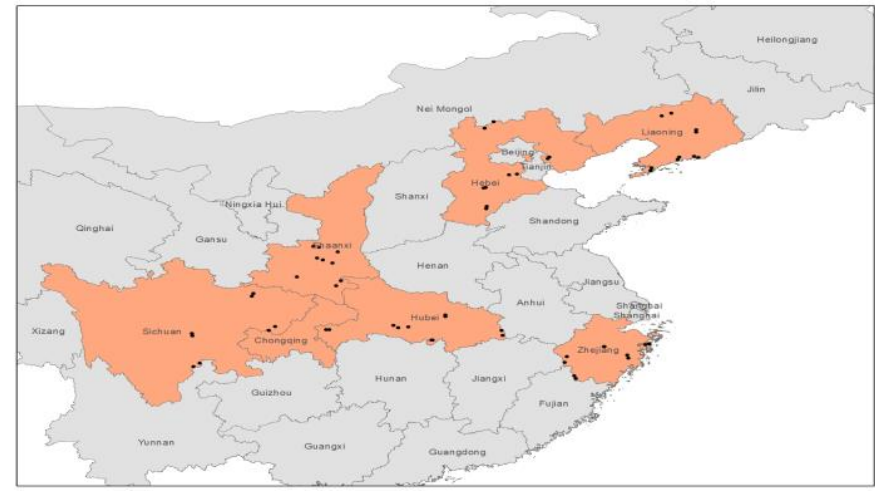

Figure 1. Map of Sample Villages

Source: IFPRI-SARI Data.

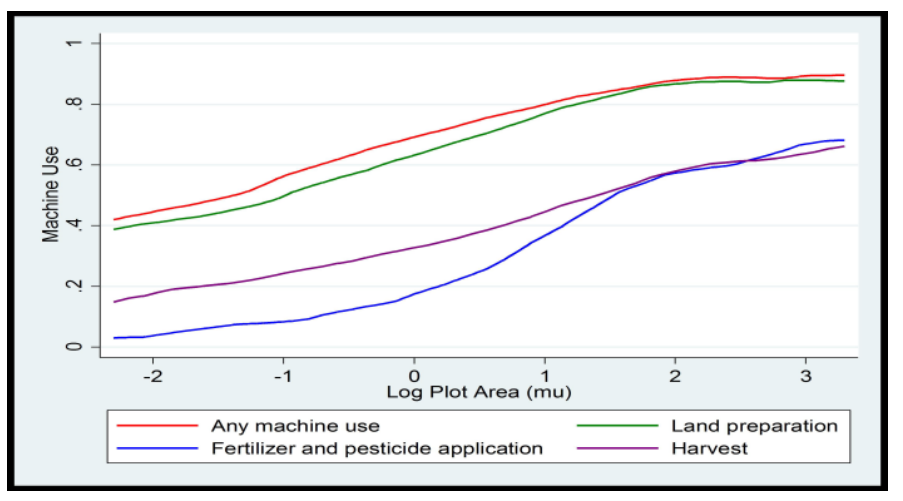

Figure 2. Proportion of machine use by production stage condi-tional on plot size, 2013

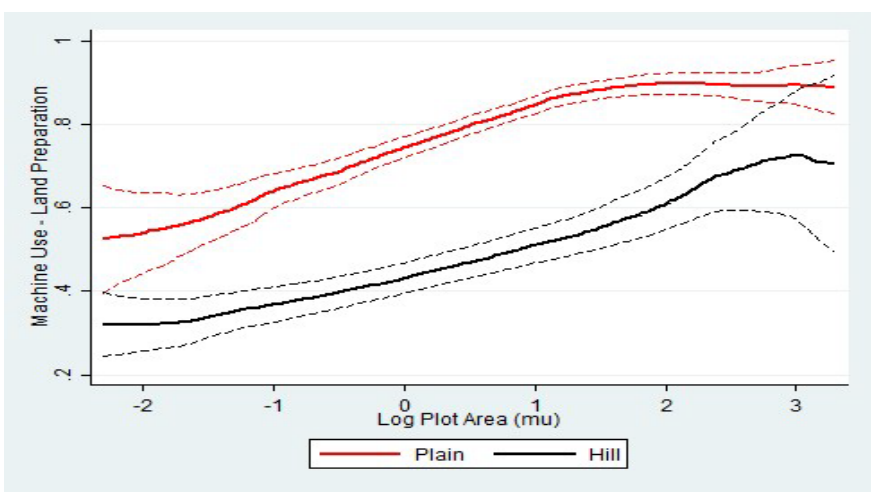

Figure 3. Proportion of machine use in land preparation conditional on plot size, by geographic location (plain or hill/mountain), 2013 


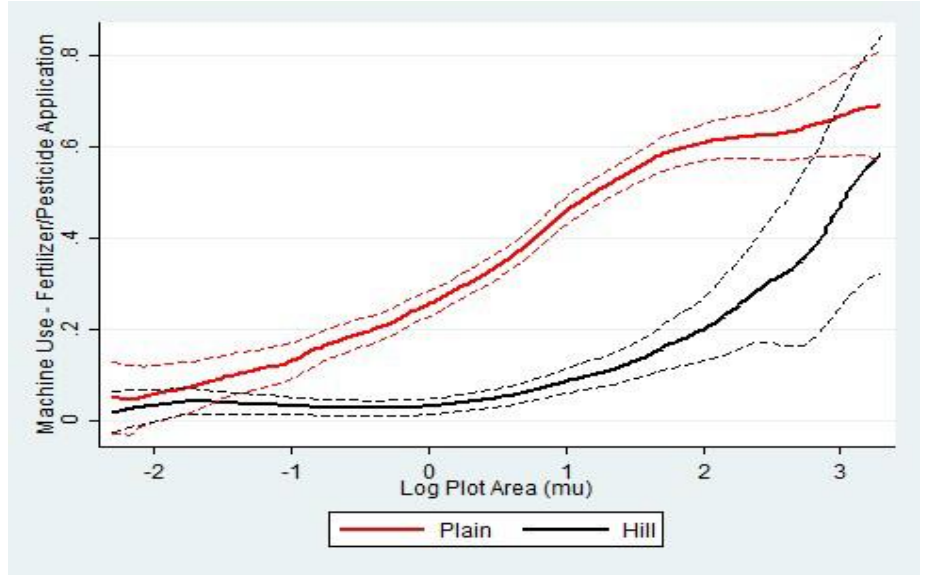

Figure 4. Proportion of machine use in fertilizer/pesticide applica-tion conditional on plot size, by geographic location, 2013

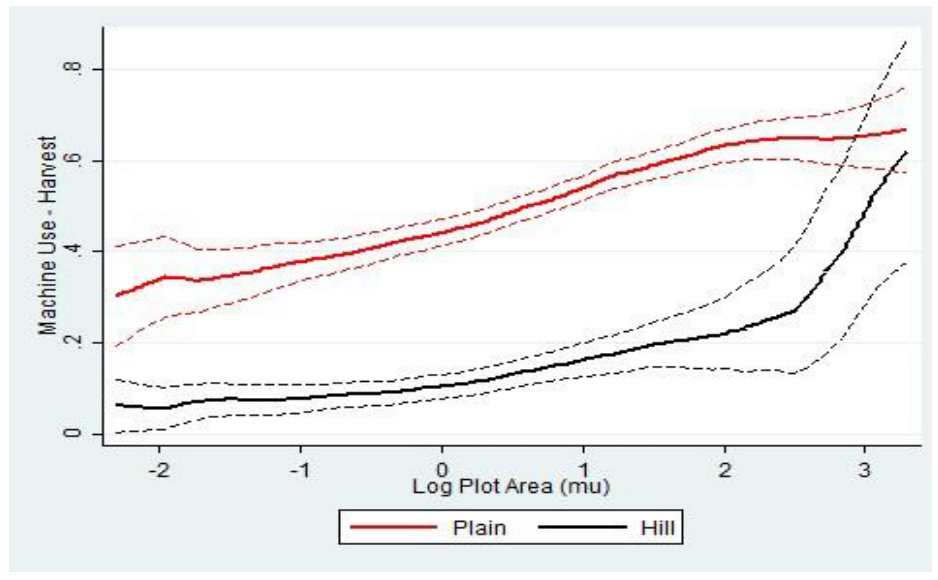

Figure 5. Proportion of machine use in harvest conditional on plot size, by geographic location, 2013

We gratefully acknowledge funding support from Syngenta Foundation for Sustainable Agriculture and the CGIAR Research Program on Policies, Institutions, and Markets (PIM).

\section{INTERNATIONAL FOOD POLICY RESEARCH INSTITUTE}

A member of the CGIAR Consortium | A world free of hunger and malnutrition

1201 I Street, NW | Washington, DC 20005 USA

$\mathrm{T}:+1.202 .862 .5600 \mid \mathrm{F}:+1.202 .467 .4439$

Email: ifpri@cgiar.org |www.ifpri.org

This publication has been prepared as an output from the project - mechanization process in Asia and its implication in SSA. It has not been peer reviewed. Any opinions stated herein are those of the author(s) and are not necessarily representative of or endorsed by the International Food Policy Research Institute.

Copyright C 2019 International Food Policy Research Institute. All rights reserved. To obtain permission to repub-

lish, contact ifpri-copyright@cgiar.org. 